\title{
Distribution of Pressures on Modified Stepped Spillway by Using Toothed-Steps
}

\author{
Jaafar S. Maatooq*, Ameer L. Jasim \\ Civil Engineering Dept., University of Technology, Baghdad, Iraq. \\ *Corresponding author Email: 40071@,uotechnology.edu.iq
}

\section{H I G H L I G H T S}

- A new stepped spillway shape was used in experimental work under the skimming flow regime by adding block (tooth) on the step.

- The tooth-stepped spillway reduces the positive and negative pressure on steps close to the crest by a large amount and especially at high discharge.

- When the spacing between tooth increase the pressure along the chute will have bad distribution compare to the traditional model.

\section{A R T I C L E I N F O}

Handling editor: Wasan I. Khalil

\begin{abstract}
A B S T R A C T
In the present study a new steeped spillway shape at which "toothed steps" have been adopted instead of traditional steps to enhance the amount and distribution of water pressure along the chute of the stepped spillway. Experiments were conducted under a skimming flow regime, on five physical models of spillway one of which consisted of traditional steps used as a base model. For all investigated models, the chute angle was $45^{\circ}$ with fourteen steeps each of $3 \mathrm{~cm}$ height. Generally, the results show that the new shape models enhance the pressure distribution and reducing the potential for negative pressures along the chute, as well as, reducing the values of positive pressures that usually impact the tread. Specifically, close to the crest, the differences in pressure values being clearly large between the toothed steps modelsand the traditional steps. The new configurations of steps reduce the positive pressures between $116.66 \%$ to $1.28 \%$ and the negative pressures were generally close to zero.
\end{abstract}

\section{Introduction}

The traditional stepped chutes and spillways have been studied extensively by many researchers over the world such as (Esery and Horner, 1978; Rajaratnam, 1990; Boes and Minor, 2002; Hazzab and Chafi, 2006; Maatooq, 2006)[1-5]. Despite this widespread employment and variety, the hydraulic behavior and efficiency of this type of chutes or spillways still require a lot of knowledge with adopting numerous features and configuration for structural development to achieve a more enhancement in hydraulic performance. One of the main features of a hydraulic performance associated is the amount of pressure and its distribution along the chute. The effects of the values and the feature of distribution will be reflected on the chute surface through cracks due to impact on tread or the emergence of cavitation effect due to arising a negative pressure along with the step rise. Many previous studies deal with the structural development of traditional steps by introducing different configurations to increase hydraulic efficiency. The improvement is done through increasing the dissipation of kinetic energy and reducing the negative effect of pressure values by re-enhancing distribution. (e.g., ChaiyuthChinnarasri\&Wongwises, 2004; Al- Lami ,2008; Bung, 2010; Hamedi et al., 2012; Felder \& Chanson, 2013 ; Ojaimi, 2013;Ahmad et al., 2014 ; Al-Shakur et al., 2014; Kathirvelan et al., 2015)[6-14]. The structural development that was adopted for these studies included; inclined upward steps, labyrinth step shape, end sills, adding baffle row or blocks at the downstream end of the step, pooled step, and Macro-roughness systems to reduce the length of inception point which will almost mitigate the risk of cavitation.

Most of the listed modifications can increase flow resistance effectively, but their attractiveness is counterbalanced by increasing the stepped spillway's structural load except that ofOjaimi (2013)[11], Maatooq and Ojaimi (2014) [15], and Maatooq (2016)[16] by using a labyrinth step instead of traditional steps. However, the attraction of additional energy 
dissipation does not optimize against the likelihood of cost increases due to the specifications of superior placement methods and the time consumed for their construction.

In the present study the new physical models, which have not been previously introduced by researchers or used in practice have been adopted in the laboratory study. In the new model, the dentate steps have been adopted instead of traditional steps to configure the form of teeth, with spaces between them. This model was operated under skimming flow conditions in order to improve the hydraulic aspects by increasing the interlocking surface areas between the mainstream and the lateral spread due to teeth sharp edges. This action leads to increasing the turbulence which creates more eddies to achieve a two-phase flow by which the energy dissipation is increased, besides reducing negative pressure values and excessive dumping forces.

\section{Theoretical background}

The pressure action was taken near the outer tread edges and near the top rise edges of selected steps, to demonstrate the distribution field along the chute face. It is known that the pressures affecting the rise are low and often have negative values, which indicates an increased occurrence of cavitation phenomenon on the rise face. While the high pressure often acts on the tread face of the step.

Juny et al (2000)[17]conduct research on stepped spillway with a slope of $1 \mathrm{~V}: 0.8 \mathrm{H}$ and relative critical depth over the crest to demonstrate the unit discharge ranging between $\mathrm{yc} / \mathrm{h}=0.891-2.246$. The authors studied the pressure distribution along the stepped chute, by using a piezo-resistive pressure transducer and flow visualizing technique. The results showed that the upper half of the rise was under negative pressures while the positive pressures were found on a horizontal face. However, the maximum and minimum pressures are located upstream of the point of inception of the boundary layer. The mean pressure shows an increasing trend towards the outer edge of tread face where the maximum value restricted near the edge at about 0.1 of tread length, whereas the mean pressure across the rise shows a decreasing trend towards the upper edge and also minimum value restricted at 0.1 of the rise length.

Chinnarasri (2002)[18] presented a formula from analyzing the results of experimental work related to the maximum time-averaged pressure Pmax on a tread face of the step, located at Hi below the crest level This is expressed as Equation (1):

$$
\frac{\mathrm{P}_{\max }}{\gamma \mathrm{H}_{\mathrm{i}}}=1.28\left(\frac{\mathrm{q}^{2}}{\mathrm{gH}_{\mathrm{i}}{ }^{3}}\right)^{0.31}
$$

Juny and Dolz (2007)[19] in their work showed the position of minimum and maximum pressure for the vertical and horizontal faces of the steps.For the horizontal faces (tread), high values are located within $0.5<\mathrm{y} / 1<0.7$-, and the maximum, however, is observed at the outer edges of the faces $y / 1=0.1$. At the vertical faces, the maximum values are restricted at the internal edge of the step when $\mathrm{z} / \mathrm{h}=1$, while the minimum value of pressure near the outer edge where $\mathrm{z} / \mathrm{h}$ is nearly equal to 0.1. Amador, et al. (2009)[20] conducted experiments on a stepped spillway of slope $1 \mathrm{~V}: 0.8 \mathrm{H}$. Mean and fluctuated pressure values were measured at both faces of the steps located in this region and close to the inception point of air entrainment. They analyzed their results in terms of the negative pressure to predict the maximum allowable discharge above which cavitation may start. From their results, they found that the unit discharges of $11.5 \mathrm{~m}^{2} / \mathrm{s}$ and $14 \mathrm{~m} 2 / \mathrm{s}$ as the onset of cavitation occurred on a prototype structure with step heights of 0.6-1.2 m, respectively.

Frizell and Renna (2011)[21] studied experimentally the potential of cavitation damage on stepped spillways of two different slopes $1 \mathrm{~V}: 2.48 \mathrm{H}$ and $2.48 \mathrm{~V}: 1 \mathrm{H}$ respectively. The roughness height in both cases was $0.05 \mathrm{~m}$. In their study, they used the cavitation index to describe the potential of cavitation along the chute slope. The cavitation index number, which is also called the special form of the Euler number, is expressed by Equation (2);

$$
\sigma=\frac{2\left(\mathrm{P}_{\mathrm{O}}-\mathrm{P}_{\mathrm{V}}\right)}{\rho \mathrm{V}_{\mathrm{O}}^{2}}
$$

Where $\sigma$ is the cavitation index, $P_{v}$ and $P_{o}$ are respectively the vapor pressure of water at a given temperature and the reference pressure, $\rho$ is the density of water and $V_{o}$ is the reference velocity. The results measured at the low ambient pressure chamber on a moderately sloped spillway revealed that cavitation is likely to form in the absence of aeration with a cavitation index of $0.6-0.7$.

Ojaimi (2013)[11] in his study used the labyrinth weir as a step configuration and named it a labyrinth stepped spillway. The experimental work was restricted to skimming flow regimes it was carried out on twelve physical models and categorized into three groups relative to chute slope $\left(35^{\circ}, 45^{\circ}\right.$, and $\left.55^{\circ}\right)$. In each group, three labyrinths stepped spillway models of three different magnification length ratios $\mathrm{L}_{\mathrm{T}} / \mathrm{W}=1.1,1.2$, and 1.3 were used. All physical models have a step height of $4 \mathrm{~cm}$ and eight steps with a total height of $32 \mathrm{~cm}$. The result shows that when magnification ratios are increased it will have a positive impact on the pressure by introducing a cushion effect which leads to reduced pressure fluctuation if compared with the performance of traditional shape, so reducing the vibration of the structure, may be attributed to the enhanced location of the inception point with labyrinth shape stepped spillway, where the increase of a magnification ratio tends to shift the inception point towards the nearest location after brink of the crest.

Husain et al. (2014)[22] showed that the maximum value of pressure on the horizontal step face inthe non-aerated flow region is located in the outer edge by about 0.22 to 0.25 of the step's treads. The region closes to the outer step edge of the step vertical face, near the inception point, is potentially subject to cavitation where the sub-atmospheric pressure values are observed. The author states that negative pressure may lead to the occurrence of cavitation on stepped spillways of moderate 
slopes in the absence of aeration. Also, the stepped chute protects the surface of the structure from cavitation damage taking advantage of the self- aeration process which allows air bubbles to enter the flow. The absence of these bubbles in a portion of the chute slope known as the non-aerated flow region could increase the risk of such damage, especially under high flow rates.

Daneshfaraz et al. (2016)[23] state that the pressure decreases along the direction so that the reduction reaches its peak value near the edge of the steps, then increases when waterfalls off the step to the next step floor, and again returns to its descending trend.

Morovati and Eghbalzadeh (2018)[14] worked on flat and pooled stepped spillway, the result showed that the negative pressure does not occur near the step bed, while it can be seen as a negative pressure adjacent to the vertical face of the step. Therefore, the cavitation phenomenon is more likely to occur on the vertical face of the step. Moreover, the cavitation phenomenon is less likely to occur in the pooled case rather than in the flat state, since fewer areas near the step surface experience negative pressure.

In the present study, the new models were not investigated before consisting of replacing the traditional step withtoothed steps. This modification leads to an increase in eddies zones, allowing more air-water interference. This hydraulic performance definitely reduces the occurrence of cavitation by preventing or reducing the likelihood of negative pressure impacts which often act on the rise of a traditional step.

\section{Experimental work}

The experimental work was carried out by using a laboratory flume in the fluid laboratory of the Civil Engineering Department, atthe University of Technology. Experiments have been carried out on five physical models with chute angles of $45^{\circ}$ under a skimming flow regime. Four models each consists of fourteen steps with different tooth distribution, furthermore, the fifth model is a traditional stepped spillway used as a base model which also has fourteen steps. Figure 1 illustrates the characteristics of these models, and the schematic representation of traditional stepped spillway with one of the new models (M1) isshown in Figures 2.

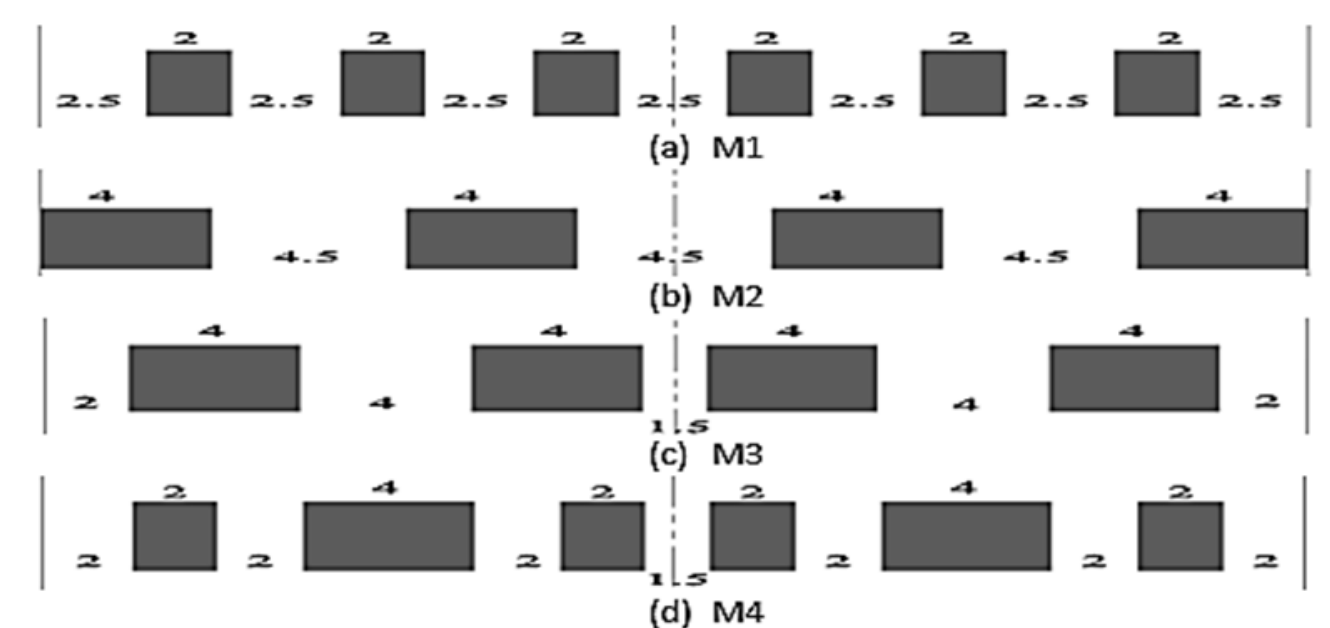

Figure 1: Plane view of toothed steps for each model (in $\mathrm{cm}$ )
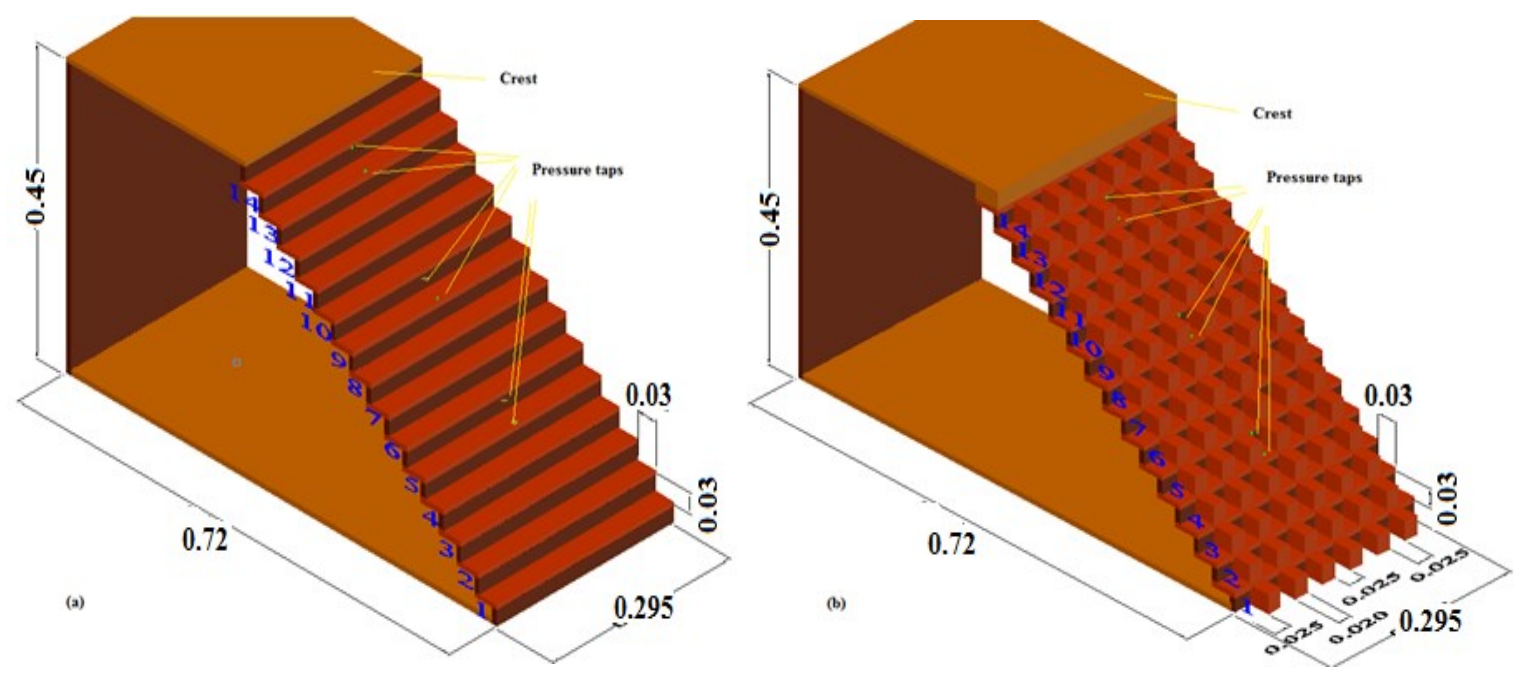

Figure 2: Figure 1: dimensions of tested model (in m) (a) traditional, (b) M1 configuration 
The maximum and minimum flow rates were $18.18 \mathrm{l} / \mathrm{s}$ and $5.35 \mathrm{l} / \mathrm{s}$, respectively which is creating a skimming flow regime along the chute. These flows creating a maximum and minimum head above the crest $12.90 \mathrm{~cm}$ and $5.45 \mathrm{~cm}$ respectively. The head was measured at a distance $1 \mathrm{~m}$ upstream the crest to overcome the drawdown action of flow profile as recommended by, Bos (1989)[25]. The geometry of crest was selected to perform broad crested weir above it the pressure distribution of flow should not deviate from a hydrostatic pressure to ensure that the streamlines are still practically straight and parallel. Thus the critical depth is obtained within the last third of the crest when keeping the head/length of the crest (H/L) between 0.07 and 0.50 as recommended by previous researchers (e.g.,Harrison, 1967;Bos 1989)[25-26]. Based on these hydraulic limitations between the available maximum and minimum heads above the crest, it was chosen that the length of the crest should be $30 \mathrm{~cm}$.

Regarding the location of maximum and minimum pressure impact on the tread and rise respectively, the previous studies related to this topic (e.g., Ojaimi, 2013; Juny et al., 2000; Matos et al. 1999; and Frizell, 2006)[11,17,27,28] concluded that the maximum pressure on a tread must be measured near the outer edge of the step, and to get an indication to a minimum pressure on the rise it must be measured as close as possible to the top edge of the step. Accordingly, the pressure taps for tread and rise have been installed in a position along the centerline of the spillway nearly the external edges. Pressure taps were installed at steps number 13, 9, and 5 which represent the locations; near the crest, at the middle of the chute, and near the toe of the spillway, respectively.

Six runs were conducted for all models as listed in Table I to simulate the variations of discharge within the limitations of the flume capacity and dimensions. Discharges were measured using an ultrasonic flow meter.

Table 1: discharges over stepped spillway physical models

\begin{tabular}{ccccccc}
\hline Run & $\mathbf{1}$ & $\mathbf{2}$ & $\mathbf{3}$ & $\mathbf{4}$ & $\mathbf{5}$ & $\mathbf{6}$ \\
\hline Discharge (1/s) & 18.18 & 15.4 & 12.69 & 10.39 & 7.96 & 5.35 \\
$\mathbf{y}_{\mathbf{c}}(\mathbf{m})$ & 0.073 & 0.066 & 0.058 & 0.050 & 0.042 & 0.032 \\
$\mathbf{y}_{\mathbf{c}} / \mathbf{h}$ & 2.429 & 2.175 & 1.912 & 1.673 & 1.401 & 1.075 \\
\hline
\end{tabular}

\section{Result and discussion}

After analyzing the experimental data, it was observed that the toothed steps had a significant effect on pressure values and distribution trends compared with the traditional stepped spillway. Increasing the teeth number and reducing the spacing between them enhance the pressure distribution along the chute under flow conditions ranged from $5.351 / \mathrm{s}$ and $18.18 \mathrm{l} / \mathrm{s}$, as illustrated via figures 3 and 4. The pressure analysis was based on the $\mathrm{L} / \mathrm{k}_{\mathrm{s}}$ ratio, in which $\mathrm{L}$ is the distance from pressure taps to the crest and $k_{s}$ is the step roughness in term of step height, $k_{s}=h \cos \theta, h$ is the step height and $\theta$ is the chute slope

The first location at the rise of a step where $\mathrm{L} / \mathrm{k}_{\mathrm{s}}=4.2$ is close to the crest. This shows the descending pressure distribution for all toothed steps models with increasing the discharge. Whereas, the distribution is oscillating and does not take a specific trend for the traditional stepped model. Figure 3a shows that the distribution of negative pressures is the result only of Model $\mathrm{M} 2$, indicating to increase in the likelihood of cavitation along the rise face of steps for all range of flow conditions. Whereas the negative pressures have occurred only at high values of discharge for the rest of the models, and the lowest values were for the M3.For the traditional model, the high-pressure values occurred in all flow conditions compared with other new models. Accordingly, the importance of using the toothed-stepped models appears through reducing the pressure values as well as eliminating the fluctuation that was the prominent feature when using the traditional stepped model.

The second location at the rise of step, where $\mathrm{L} / \mathrm{k}_{\mathrm{s}}=11.85$, is in mid of chute. This shows that the ascending pressure distribution for all models with increasing the flow rate. However, the traditional model has an almost negative pressure value for all discharges. Accordingly, this increases the probability of cavitation as mention before. While the teethed-steps models have a positive pressure for mid and high discharge and negative pressure occurs only in low discharge. Also, M2 shows different pressure behavior compare to other teethed step models, the pressure increases dramatically with discharge, see Figure $3 \mathrm{~b}$. At this point, the teethed-steps models show a high ability to reduce the negative pressure compare with traditional stepped spillways without any oscillating or fluctuation.

The last location at the rise of a step where $\mathrm{L} / \mathrm{k}_{\mathrm{s}}=19.49$ is located near the toe. This shows increasing pressure distribution for both teethed step model and the traditional model with increasing the flow rate. Furthermore, the toothed models have only a positive pressure for all discharges with some fluctuation in low discharge for M1 and M4. However, the negative pressure occurred in the small discharge for the traditional stepped spillway as illustrated in Figure $3 \mathrm{c}$. In addition, using a toothed model will eliminate the possibility of cavitation risk at this location by preventing the occurrence of negative pressure.

The pressure at the tread of step, where $\mathrm{L} / \mathrm{k}_{\mathrm{s}}=5.73$, is close to the crest. This indicated that dropping pressure distribution for all toothed steps models toward zero with increasing the discharge and some fluctuation accrues in low flow rate. While the pressure distribution for all flow conditions is positive without any fluctuation or oscillating for the traditional stepped spillway. However, teethed step models have less positive pressure than the traditional stepped spillway. The negative pressure result only in M2 with a value closes to zero as shown in Figure 4a. Thus, the importance of using teethed model is reducing the positive pressure on step tread especially in high discharge which prevents the likelihood of crushing the step due to high pressure value.

The pressure at the tread of a step where $\mathrm{L} / \mathrm{k}_{\mathrm{s}}=13.37$ is located at the mid chute. This shows positive pressure for toothedstepped models and for all flow condition with increasing of pressure distribution when discharge increase. Furthermore, the pressure is positive, and the distribution is oscillating and does not take a specific trend for the traditional stepped model as shown in Figure 4b. Also, the pressure in low discharge for Toothed-Steps models is less compared to the traditional model, 
and the pressure distribution for new models hasan almost constant trend. At this location the new models show a good performance in reducing the fluctuation of pressure through increasing the air presence inflow which creates more cushion effect, this may be attributed to the enhancement of inception point location with toothed models. This agreed with Amador et al., (2004)[29] where they concluded that the presence of air inflow introduces cushion effect, then reduces the pressure fluctuation. Also, the same results were noticedby Ojaimi (2013)[11].

The pressure at the tread of step, where $\mathrm{L} / \mathrm{k}_{\mathrm{s}}=21.02$, near the toe of the spillway, increasing with increasing of discharge for all model. Furthermore, the pressure was positive for all flow conditions in both teethed-Steps models and traditional ones. Also, the pressure in teethed-steps models is less than that of the traditional model, except for M2 it was greater, as illustrated in Figure 4c. Moreover, at this location, the cushion effect can be also noticed through the constant trend for almost all models because of the high air presence at a point close to the toe of the spillway

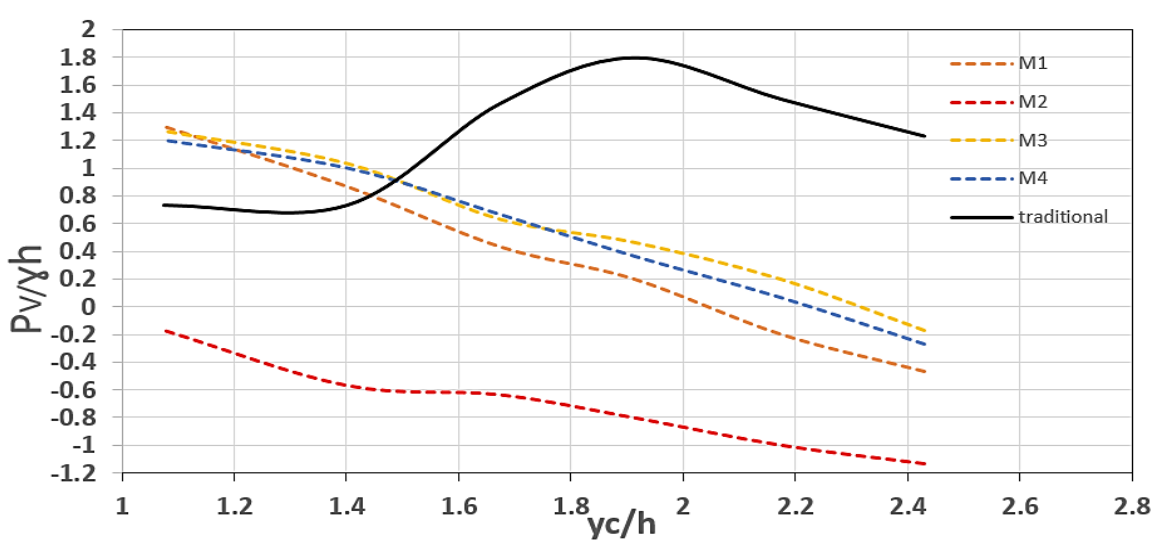

Figure 3: A pressure distribution against the rise of step for the model (M1-M4) and traditional with $(\mathrm{L} / \mathrm{ks}=4.2)$

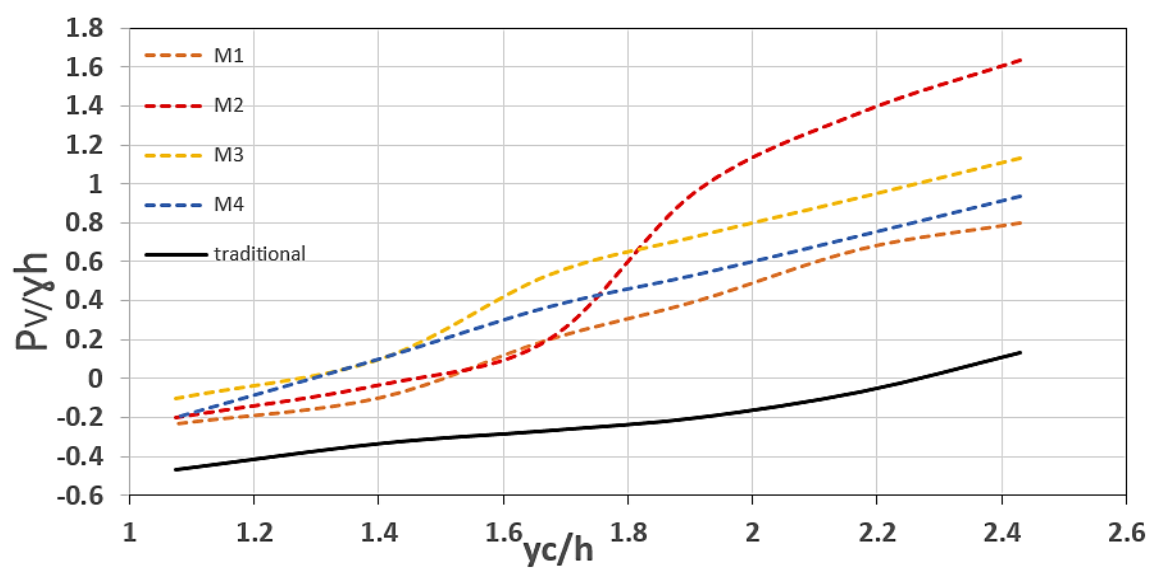

Figure 3: B pressure distribution against the rise of step for the model (M1-M4) and traditional with $\left(\mathrm{L} / \mathrm{k}_{\mathrm{s}}=11.85\right)$

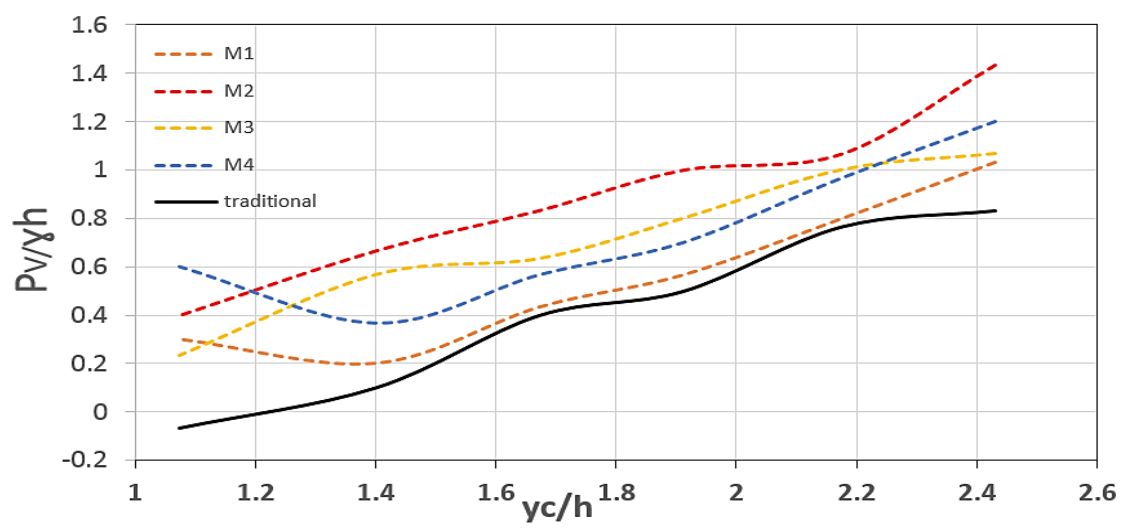

Figure 3: C pressure distribution against the rise of step for the model (M1-M4) and traditional with $\left(\mathrm{L} / \mathrm{k}_{\mathrm{s}}=19.49\right)$ 


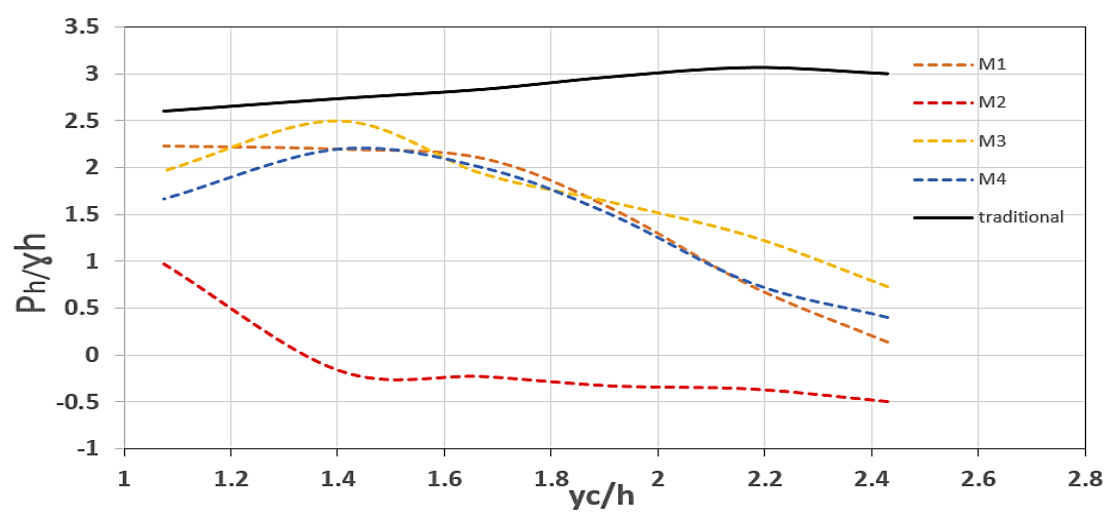

Figure 4: A pressure distribution against the tread of step for the model (M1-M4) and traditional with $\left(\mathrm{L} / \mathrm{k}_{\mathrm{s}}=5.73\right)$

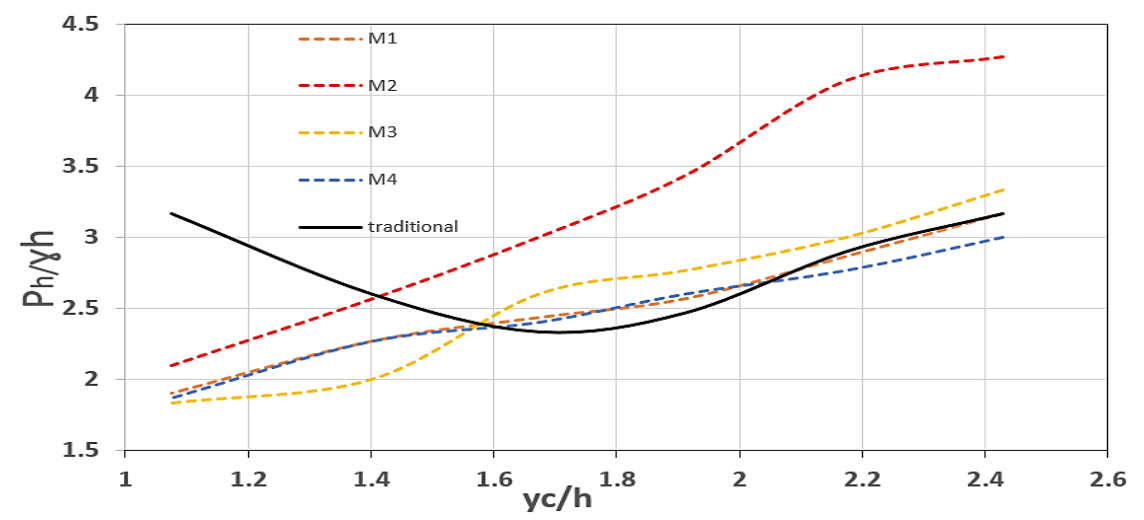

Figure 4: B pressure distribution against the tread of step for the model (M1-M4) and traditional with $(\mathrm{L} / \mathrm{ks}=13.37)$

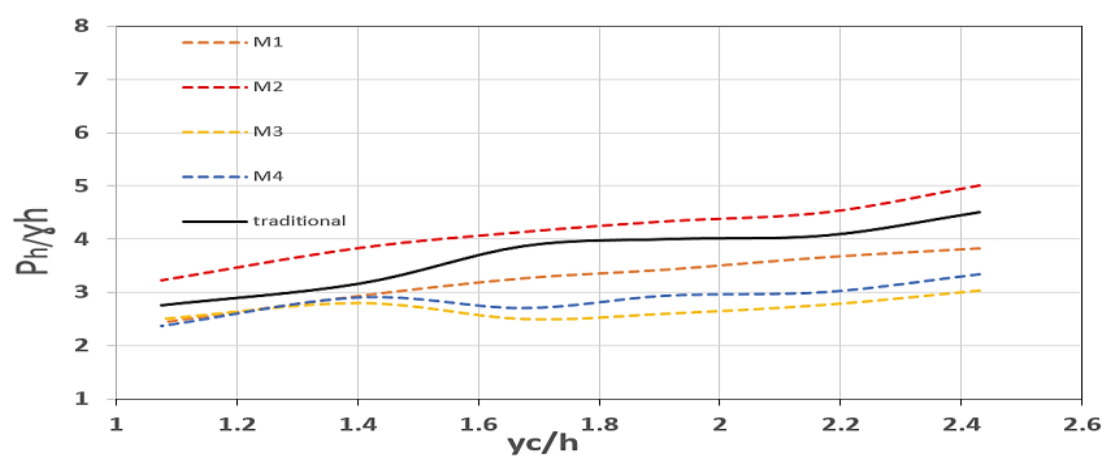

Figure 4: $C$ pressure distribution against the tread of step for the model (M1-M4) and traditional with $\left(\mathrm{L} / \mathrm{k}_{\mathrm{s}}=21.02\right)$

\section{Conclusions}

The analysis of the values and distribution of pressure against rise and tread of the toothed steps spillway and traditional stepped spillway under skimming flow regime with flow rate range between 5.351/s and 18.181/s have been accomplished. The following conclusions can be drawn.

1) Overall intoothed-steps models the pressure values were enhanced along the chute by reducing the likelihood of negative pressures, as well as reducing the positive pressure, through directing the values to approach zero. The new configurations of steps reduce the positive pressures between $116.66 \%$ to $1.28 \%$ for modelsM1, M3, and M4.That means the toothed- steps model is better than the traditional shape in terms of pressure distribution.

2) At point close to the crest, the result shows a large difference in pressure value between the toothed models and the traditional one with the advantage of the toothed models by reducing the positive pressure value except for M2 which have only negative pressure. The pressure at this location is highly influenced by the rate of flow for both traditional and teethed stepped models.

3) The new models create more cushion effect leads to a reduction of pressure fluctuation if it compared with a traditional shape, this may be attributed to the enhancement of inception point location with toothed 
models. That agreed with Amador et al., (2004)[29]where they concluded that the presence of air inflow introduces cushion effect, then reduces the pressure fluctuation. This consequence has also been confirmed byOjaimi (2013)[11].

4) M2 model, have a dramatic shift in the pressure values from positive to negative values has been noted, especially near crest at step tread, in addition to some increase in the positive values on other treads located at the middle and close to the toe than those recorded when using the traditional model. Through these observations, the M3 model does not have a positive addition in terms of hydraulic performance as an alternative to using the traditional model in terms of the pressures recorded on either the rise or the tread of steps. Thus, it is not recommended to use it in applications.

\section{Author Contribution}

All authors contributed equally to this work.

Funding

This research received no specific grant from any funding agency in the public, commercial, or not-for-profit sectors.

Data Availability Statement

The data that support the findings of this study are available on request from the corresponding author.

\section{Conflicts of Interest}

The authors declare that there is no conflict of interest.

\section{References}

[1] I. T. S. Esery and M. W. Horner, “The hydraulic design of stepped spillway,” CIRIA Rep., vol. 33, 1978.

[2] N. Rajaratnam, “SKIMMING FLOW IN STEPPED SPILLWAYS,” vol. 116, no. 4, pp. 587-591, 1990.

[3] R. Boes and H.-E. Minor, "Hydraulic design of stepped spillways for RCC dams.," Int. J. Hydropower Dams, vol. 9, no. 3, pp. 87-91, 2002.

[4] A. Hazzab and C. Chafi, "Experimental Investigation of Flow and Energy Dissipation in Stepped Spillways," Recherche, pp. 91-104, 2006.

[5] J. S. Maatooq, "Stepped spillway hydraulic model investigation,” Tikrit Journal of Engineering Sciences, vol. 13, no. 3, pp. 103-120, 2006.

[6] C. Chinnarasri and S. Wongwises, "Flow regimes and energy loss on chutes with upward inclined steps," Can. J. Civ. Eng., vol. 31, no. 5, pp. 870-879, 2004, doi: 10.1139/L04-052.

[7] Al- Lami, M. K.(2008)," Study of Conveniency of Using Stepped Spillway in Roller Compacted Concrete Dams (RCCD)". M.Sc. Thesis, University of Technology, Baghdad, Iraq.

[8] D. B. Bung, "A Comparative Study of Self-aerated Stepped Spillway and Smooth Invert Chute Flow: The effect of Stepinduced Macro-roughness," pp. 3-7, 2010.

[9] A. Hamedi, I. Malekmohammadi, A. Mansoori, and H. Roshanaei, "Energy dissipation in stepped spillway equipped with inclined steps together with end sill," Proc. - 4th Int. Conf. Comput. Intell. Commun. Networks, CICN 2012, pp. 638-642, 2012, doi: 10.1109/CICN.2012.109.

[10] S. Felder and H. Chanson, “Air Entrainment and Energy Dissipation on Porous Pooled Stepped Spillways,” IWLHS 2013 - Int. Work. Hydraul. Des. Low-Head Struct., no. 2012, pp. 87-97, 2013.

[11] Ojaimi, T. Y. (2013)" Evaluation of the Hydraulic Aspects for Step Labyrinth Spillway". M.Sc. Thesis, University of Technology, Baghdad, Iraq.

[12] N. Ahmad, R. E. Baddour, and M. Asce, "Inception Point of Air Entrainment and Training Wall Characteristics of Baffles and Sills on Stepped Spillways," J. Hydraul. Eng., vol. 139, no. July, p. 04016035, 2014, doi: 10.1061/(ASCE)HY.

[13] P. A. K. Al-shukur, S. K. H. Al-khalaf, and I. M. A. Al-sharifi, "Flow Characteristics and Energy Dissipation Losses in Different Configurations of Steps of Stepped Spillway," vol. 3, no. 1, pp. 8823-8832, 2014.

[14] C. Kathirvelan, D. Premchandar, M. R. Purushothaman, P. Vasanthakumar, and D. Chandrasekaran, "Energy Dissipation of Skimming Flow with Different Sill Dimensions in Stepped Spillway Model,” Mortality, vol. 4, no. 2, pp. 64-68, 2015.

[15] J. S. Maatooq and T. Y. Ojaimi, "Evaluation the Hydraulic Aspects of Stepped Labyrinth Spillway,”Engineering and Technology Journal. University of Technology, vol. 32, no. 9, pp. 2174-2185, 2014. 
[16] J. S. Maatooq, “Kinetic Energy Dissipation on Labyrinth Configuration Stepped Spillway,"Tikrit Journal of Engineering Sciences, vol. 22, no. 1, pp. 76-93, 2016.

[17] M. Sánchez-Juny, J. Pomares, and J. Dolz, "Pressure field in skimming flow over a stepped spillway," Proc. Int. Work. Hydraul. Stepped Spillways, pp. 137-146, 2000.

[18] C. Chinnarasri, "Assessing the flow resistance of skimming flow on the step faces of stepped spillways," Dam Eng., vol. 12, no. 4, pp. 303-322, 2002.M.

[19] M.Sánchez-Juny, E. Bladé, and J. Dolz, "Pressures on a stepped spillway,” J. Hydraul. Res., vol. 45, no. 4, pp. 505-511, 2007, doi: 10.1080/00221686.2007.9521785.

[20] A. Amador, M. Sánchez-Juny, and J. Dolz, "Developing flow region and pressure fluctuations on steeply sloping stepped spillways,” J. Hydraul. Eng., vol. 135, no. 12, pp. 1092-1100, 2009, doi: 10.1061/(ASCE)HY.1943-7900.0000118.

[21] K. W. Frizell and F. M. Renna, "Laboratory studies on the cavitation potential of stepped spillways," in Proceedings of the 34th world congress of the international association for hydro-environment research and engineering: 33rd hydrology and water resources symposium and 10th conference on hydraulics in water engineering, 2011, p. 2420.

[22] S. M. Husain, J. R. Muhammed, H. U. Karunarathna, and D. E. Reeve, "Investigation of pressure variations over stepped spillways using smooth particle hydrodynamics," Adv. Water Resour., vol. 66, pp. 52-69, 2014, doi: 10.1016/j.advwatres.2013.11.013.

[23] R. Daneshfaraz, A. R. Joudi, A. Ghahramanzadeh, and A. Ghaderi, "Investigation of flow pressure distribution over a stepped spillway," Adv. Appl. Fluid Mech., vol. 19, no. 4, p. 811, 2016.

[24] K. Morovati and A. Eghbalzadeh, "Study of inception point, void fraction and pressure over pooled stepped spillways using Flow-3D,” Int. J. Numer. Methods Heat Fluid Flow, vol. 28, no. 4, pp. 982-998, 2018, doi: 10.1108/HFF-03-20170112.

[25] A. J. M. HARRISON, “the Streamlined Broad-Crested Weir,” Proc. Inst. Civ. Eng., vol. 38, no. 4, pp. 657-678, 1967, doi: 10.1680/iicep.1967.8193.

[26] M.G.Bos, "Discharge measurements Structures" (e.d.), Publication 20, ILRI 3rd ed., Netherlands, 1989.

[27] J. Matos, M. Sánchez-Juny, A. Quintela, and J. Dolz, "Characteristic depth and pressure profiles in skimming flow over stepped spillways,” XXVIII IAHR Congr., vol. Graz, Aust, 1999.

[28] K. H. Frizell, "Research state-of-the-art and needs for hydraulic design of stepped spillways," Hydraul. Lab. Report. U. S. Bur. Reclam., p. 65, 2006

[29] A. Amador, M. Sanchez-Juny, J. Dolz, F. Sanchez-Tembleque, and J. Puertas, "Velocity and pressure measurements in skimming flow in stepped spillways," in Proc. Intl Conf. on Hydraulics of Dams and River Structures, 2004, pp. $279-285$. 